\title{
The Problem of Fire Control by Automatic Fire Extinguishing System
}

\author{
Leonid Tanklevskiy ${ }^{{ }^{*}}$, Aleksandr Tarantsev ${ }^{2,3}$, Ivan Balabanov ${ }^{1}$, Elena Murashkevich ${ }^{3}$, \\ Denis Lobov', and Anton Mel'nik ${ }^{3}$
}

${ }^{1}$ Peter the Great St. Petersburg Polytechnic University, 195521 Polytechnicheskaya, 29, SaintPetersburg, Russia

${ }^{2}$ N. S. Solomenko Institute of Transport Problems of the Russian Academy of Sciences, 199178, St. Petersburg, Russia

${ }^{3}$ FSBEE HE «Saint-Petersburg University of State Fire Service of EMERCOM of Russia», 196105, Moskovsky prospect, 149, Saint-Petersburg, Russia

\begin{abstract}
According to Article 117 of Russian Federal Law 123 of 2008, there is a class of objects historical buildings, exhibition complexes, energy facilities, etc. For these objects, it is not so necessary to eliminate the fire with automatic fire extinguishing systems, as to contain it until the arrival of fire departments. However, this law does not specify certain requirements for automatic installations, the main working substance of which is water and the solutions. The current situation makes it difficult to design, install and test automatic fire control systems. Given this, as well as the foreign experience and domestic developments in the field of automatic fire extinguishing systems, it is important to conduct a special research work. In this work, it is necessary both to conduct several fire tests in terms of the development of a fire with a limited water supply intensity, and to develop a draft of standard "Water automatic fire containment installations. General technical requirements. Test methods".
\end{abstract}

\section{Introduction}

Automatic fire extinguishing system [1-4] designed for fire elimination and lockout, by now have found wide application in fire protection systems in different classes of functional fire hazard $[5,6]$ in our country as well as abroad.

Modern fire protective equipment is divided by their constructive embodiment into sprinkler system, deluge system by the type of fire extinguishing agent into water, foam, gas, powder, aerosol, etc. It is divided into extinguishing: by surface, volume, local volume, and local surface; by the start methods: manual, automatic, etc.; by performance - modular, stationary, robotic, etc.; and have different inertia and duration of fire extinguishing agent supply.

\footnotetext{
*Corresponding author: tanklevskiy@gmail.com
} 
However, Article 117 of the Federal Law [5] assigns the need to create a new kind of automatic installations designed to contain the fire. They should: a) provide decrease in rate of fire area increase and formation of its dangerous factors; b) be applied in the premises where application of other dangerous factors is inexpedient or technically impossible. Peculiarities of automatic fire prevention systems.

As shown in the report [7], the automatic fire control system are applicable to: - objects of historical and cultural heritage: theaters, museums, exhibition complexes, etc.; - Power installations [8] where class B and E fires are possible [5];

- Medical and scientific institutions.

- large areas where there are no fire protection barriers, including high rack warehouses [9], workshops, underground parking lots [10], etc;

- high-rise buildings and structures [11];

- objects in cold climatic zones, where it is difficult to maintain a constantly heated supply of the water for automatic fire extinguishing systems.

The type of the protective agents in the fire extinguishing system should be determined by the characteristics of the protected object, the type and location of the fire load. Given that the most common fire extinguishing agent is water and its solutions, it is important to focus on extinguishing agents.

Also, the report [7], taking into account the work [12, 13] and foreign experience [4] shows that the requirements of article 117 [5] are achievable under the following conditions: - the damage from secondary agents, i.e. excessively applied (spilled water), can exceed the damage from primary such as flame, thermal radiation, etc. [5];

- the supply of water is limited, for example, in arid areas or in areas with extremely low temperatures [14];

- there is a fire department, which ensures the beginning of extinguishing in minimum time and before the arrival of fire departments the exit area of which includes the protected object; - the protected object contains substances, materials, equipment, etc. which are undesirable or dangerous to come into contact with the used fire extinguishing agents;

- a sprinkler fire control system previously installed in the protected object, due to the height of its location where it is not possible to effectively eliminate fire $[2,17]$ and in this system passes into the category of automatic fire extinguishing equipment;

- automatic fire control system at facilities of fire hazard class F5 [5] must, if necessary, create curtains preventing or limiting the development of fire factors from the burning zone (flame, sparks, toxic products of combustion) to other parts of the premises, buildings, structures, including evacuation routes [15] and high rack storage area [9];

- the automatic fire control system should protect large areas of glazing (especially in highrise buildings [11]) and storage above 5,5 $\mathrm{m}$ [9].

\section{Materials and methods}

In a similar way with works $[16,7,12,13]$ set out the basic requirements for the automatic fire extinguishing system:

1. The area of fire $\mathrm{Sn}$ at the time of arrival and delivery of trunks to extinguish the first fire unit $\tau 1$ should be contained to the size of the area St, which can extinguish a unit of gas firefighting service [18], ie:

$$
\operatorname{Sn}(\tau 1)<\operatorname{St}(\tau 1)
$$

If condition (1) is satisfied at the rated linear velocity of fire propagation V1 [21], so use automatic fire control system is not required. 
2. On the evacuation routes, the fire factors must be contained until the evacuation is complete (this is typical for historical buildings with non-normative evacuation routes, hospitals [19], etc.).

3. To avoid the limiting condition of any of the building structures [20], the fire factors (first of all, the flame, increased temperature and heat flow) must be contained, before the firefighters supply the barrels for its protection.

To fulfill the $1^{\text {st }}$ requirement, it is necessary to estimate: a) the time $\tau 1$ (receiving the message about the fire, gathering and following of the fire unit, combat deployment and supplying of hoses); b) the areas St and Sn.

The magnitude of the area St can be determined by the expression:

$$
S_{\text {т }}=n \frac{q}{I_{\text {н }}}
$$

where $n$ is the number of nozzles which can be extinguished by the first fire-unit arriving (as a rule, $n=2$ ); $\mathrm{q}$ is the water flow from the nozzle (e.g. for the nozzles "B" $q=3,5-3,7$ 1/sec used on the premises); In is the required surface water supply intensity for extinguishing (e.g. for industrial buildings $I_{n}=0,20-0,35 \mathrm{~lm}$ per $2 \mathrm{sec}$ ). The value of area $S_{n}$ can be determined by the expressions in Table 1.

Table 1. Formulas for determining the area Sn depending on the form, duration and speed of fire spread.

\begin{tabular}{|c|c|c|}
\hline \multirow{2}{*}{ Time } & \multicolumn{2}{|c|}{ Form of fire } \\
\cline { 2 - 3 } & Circular and partially circular & Linear \\
\hline $\begin{array}{c}\tau_{1} \leq 10 \\
\min \end{array}$ & $S_{\mathrm{n}}=k_{\mathrm{f}} \pi\left(0,5 V_{\mathrm{dop}} \tau_{1}\right) 2$ & $S_{\mathrm{n}}=0,5 \mathrm{k}_{1} V_{\mathrm{dop}} A \tau_{1}$ \\
\hline $\begin{array}{c}\tau_{1}>10 \\
\min \end{array}$ & $S_{\mathrm{n}}=k_{\mathrm{f}} \pi\left[V_{\mathrm{dop}}\left(\tau_{1}-5\right)\right] 2$ & $S_{\mathrm{n}}=\mathrm{k}_{1} V_{\mathrm{dop}} A\left(\tau_{1}-5\right)$ \\
\hline
\end{tabular}

Notes:

$V_{\text {dop }}$ - permissible linear velocity of fire propagation.

$k_{\mathrm{f}}$ - a shape factor (in case of fire in the center of the room $k_{\mathrm{f}}=1$; in case of fire near the wall $k_{\mathrm{f}}=0,5$; in case of fire in the corner of the room $k_{\mathrm{f}}=0,25$ );

$A$ - the width of the corridor or a rectangular premise;

$k_{1}$ - the number of directions of combustion propagation $\left(k_{1}=1\right.$ when the combustion spreads to one side, $k_{1}=2$ when the combustion spreads to both sides along the whole width of the room a).

The permissible velocity $V_{\text {dop }}$ of fire propagation, when $S_{\mathrm{t}}=S_{\mathrm{n}}$, can be determined by the expression:

$$
\begin{aligned}
& V_{\text {dop }}=K_{\mathrm{T}}\left\{\begin{array}{l}
\sqrt{\frac{S_{\mathrm{T}}}{k_{f} \pi}} \\
\frac{S_{\mathrm{T}}}{k_{l} a}
\end{array}\right. \\
& K_{\mathrm{T}}=\left\{\begin{array}{l}
2 \tau_{1}^{-1}, \tau_{1}<10 \mathrm{~min}, \\
\left(\tau_{1}-5\right)^{-1}, \tau_{1} \geq 10 \mathrm{~min}
\end{array}\right.
\end{aligned}
$$

The required irrigation intensity of automatic fire control system can be estimated by the formula:

$$
I_{\text {тр }}=I_{H}\left(1-\frac{V_{\mathrm{dop}}}{V_{l}}\right) \frac{k_{z} \tau_{1}}{\tau_{1}-\tau_{A}}
$$

Where $\tau_{A}$ is the delay time of switching on the fire control system, counted from the beginning of fire, min.

$k_{\mathrm{z}}$ is a safety factor of the order of 1.1-1.3.A 


\section{Results and discussion}

Determination of the linear velocity of fire propagation over the fire load under conditions of its sprinkling can be determined experimentally, for example, on the experimental base of St. Petersburg State Fire Service of the Ministry of Emergency Situations of Russia.

The water curtain designed to protect walls should consist of two strings with sprinklers; the specific flow rate of each curtain is at least $0,5 \mathrm{sec} / 1 \mathrm{~m} / 1$.

To protect translucent partitions up to EI60 values, sprinkler systems should be installed along the protected partition so as to ensure the sprinkling of the latter with a specific flow rate of at least $0,261 \mathrm{sec} / 1 \mathrm{~m} / 1$. Depending on the architectural and planning solutions, the activation of irrigation systems can occur simultaneously along the entire length of the partition in the room where the fire occurred/detected, or only on a part of it. Sprinkler systems may be installed in a single string on the side of the room with a fire load spacing of not more than $1,5 \mathrm{~m}$. The distance from the axis of the sprinkler system to the partition is from 0,1 to $0,5 \mathrm{~m}$ inclusive.

Separately we can mention the Arctic facilities, where due to the extremely cold climate the use of water for fire extinguishing is extremely problematic. In this regard, it was proposed to purge the volumes of Arctic modules with external low-temperature air by incorporating the built-in purging system [14], which will delay the development of the fire and ensure the safe operation of the arriving fire department.

Thus, researches in the field of fire-prevention allow to create a project of the new normative document - standart and to concretize thereby positions of article 117 of the Federal law [5]. In practice, when using the developed standart, it becomes possible to create automatic fire control system, protecting a number of objects by holding back the CFP by water supply until the arrival of fire department or/and the end of the evacuation of people, when the use of other automatic fire control system is inexpedient or technically impossible. In the future, it seems necessary to develop an appropriate Hand Book in terms of requirements for the automatic fire control system and calculation estimates of its parameters.

\section{Conclusion}

In the frame work of this research the standard of this system was developed considering the fact that the notion of a, being introduced in the Federal Law [5], practically was not mentioned in other normative documents of fire protection, there is a task of formalizing a special document, where the requirements to automatic fire control system are specified according to the list of protected objects, according to the type and intensity of spray agent, fire containment time, etc.

This standard "Automatic water fire-retarding installations. General technical requirements. Test methods" was developed within framework of collaboration between "organization GK Gefest" and Saint-Petersburg University of State Fire Service of EMERCOM of Russia and Saint-Petersburg Polytechnic University Peter the Great.

\section{References}

1. Standart 12.3.046-91 "SSBT. Automatic fire-extinguishing installations. General technical requirements".

2. Hand Book 485.1311500.2013 "SPPZ. Automatic fire extinguishing installations. Design norms and rules".

3. Automatic fire extinguishing installations. AUP-GEFEST. Design. STO 420541.004. VNPB 40-16. Moscow: EMERCOM of Russia, 2016. -p56. 
4. NFPA 13. Standard for the Installation of Sprinkler Systems. Quincy, Massachusetts, NFPA, 2016, p496.

5. Federal Law of 22.07.2008 № 123 (as amended) "Technical regulation on fire safety requirements".

6. V.V. Krymsky, A.E. Pankov. Risk-Controlling System of Industrial Enterprise // Scientific and Technical Bulletin of St. Petersburg Polytechnic University, No. 2 (192), 2014. -.p114-122 .

7. L.T. Tanklevsky, Tarantsev A.A., Tanklevsky A.L., Kovrignykh T.K., Zybina O.A. Development of the normative document in terms of forming the requirements to the AUTOMATIC FIRE ONTROL SYSTEM/ / XXXIII International Scientific and Technical Conference devoted to the year of science "Actual Problems of Fire Safety. MOSCOW: VNIIPO, 2021. p.363-369.

8. STO 56947007-33.040.10.118-2012 "Fire Extinguishing Systems at the Facilities of Federal Grid Company of Unified Energy System. General technical requirements".

9. Hand Book 241.1311500.2015 "SPPZ. Automatic water fire extinguishing installations of high rack warehouses. Design norms and rules".

10. Hand Book 154.13130.2013 "Built-in underground parking lots. Fire safety requirements".

11. Hand Book 477.1325800.2020 "Tall Buildings and Complexes. Fire safety requirements".

12. L.T. Tanklevsky, On peculiarities of application of automatic fire containment installations / A.I. Bondar, E.A. Meshalkin, L.T. Tanklevsky, S.G. Tsarichenko, A.A. Tarantsev // "Fire and explosion safety" - 2019. - №6 (т.28). - p.71-79. DOI: 10.18322/PVB.2019.28.06.71-79

13. L.T. Tanklevsky, On the problem of developing automatic fire containment installations / L.T. Tanklevsky, O.A. Zybina, A.A. Tarantsev // Scientific journal "Problems of risk management in the technosphere". - 2019. - №4 [52]. - C.67-72.

14. A.A. Tarantsev, On the justification of innovative way to extinguish a fire at infrastructure facilities at low temperatures / A.A. Tarantsev, A.D. Ishchenko, A.A. Tarantsev // Marine Intelligent Technologies. - 2021. - №1 [42]. - p.84-89.

15. Hand Book 1.13130.2020 "SPPZ. Evacuation routes and exits".

16. Hand Book 11.13130.2009 Places of Dislocation of Fire Fighting Units. Procedure and Methods of Determination (with Change № 1).

17. L.T. Tanklevsky, Evaluation of effectiveness of fire sprinkler systems / L.T. Tanklevsky, A.Yu. Snegirev, L.M. Meshman, A.S. Tsoy, S.N. Kopylov, A.A. Tarantsev // "Fire Safety", 2015. - №1. - p.72-79.

18. Order of the Ministry of Emergency Situations of Russia from October 16, 2017 № 444 "On approval of the Combat Statute of fire protection units, which defines the order of organization of fire extinguishing and emergency rescue work".

19. A.A. Semin, A.M. Fomin, V.V. Kholschevnikov, Problem of safe evacuation of patients in medical institutions in case of fire, "Fire and explosion safety". - 2018. - No. 7-8 (vol. 27).- p. 74-88. DOI:10.18322/PVB.2018.27.7-8.74-88.

20. V.M. Roitman, Engineering solutions for assessing the fire resistance of designed and reconstructed buildings. - Moscow: Association "Fire Safety and Science", 2001. p382.

21. V.V. Terebnev, Handbook of the Head of Fire Fighting. Moscow: Izd vo "PozhKniga," 2004. - p248 